\title{
Editorial PUBLISHING: ARE WE ON THE RIGHT TRACK?
}

Publication is an essential part of scientific work. The dissemination of results represents a fundamental step in expanding basic knowledge to foster the development of innovative, more effective, less costly and/or more environmentally friendly technologies or processes. This was the initial intention underlying the publication of research studies and remains valid today. Publication nowadays represents an integral part of education, and whilst it is not expected that a master or $\mathrm{PhD}$ thesis will necessarily result in the identification of new inventions or fundamental processes, a series of stepping stones may be added to our specific knowledge. When considering the vast number of theses produced worldwide, the more innovative could indeed contribute towards furthering knowledge and producing new technologies or developments.

In order to progress in our scientific careers, there is a general "requirement" to produce innovative results on a yearly basis. A certain number of publications, preferably in high impact factor scientific journals, are mandatory prior to gaining authorization to proceed with a $\mathrm{PhD}$ viva or in achieving qualifications for an academic career. Considerable pressure is therefore placed on students and academics at Universities and research institutions. Of course, the idea behind this approach is to encourage researchers and students in undertaking their studies and publishing the results obtained. However, research is not predictable, it is time-consuming and failures do occur. Indeed, I still have the - perhaps romantic idea - that researchers are very much devoted to working under their own incentive...

This impelling need for publications resembles the sword of Damocles hanging over the academic community. If, for a series of reasons, adequate material for publication is not available, an alternative means of "survival" will need to be identified. For this reason, research results suitable for presentation in a single paper may be divided into a series of potential publications. Moreover, increasingly lengthy lists of authors may be acknowledged on the paper although their input is not always clear; at times it is almost as if names are included merely to boost the individual's number of publications. This practice has been manifested as the result of the stringent requirements relating to number of required publications per year.

Indeed, when evaluating the scientific merit of an academic, the number of publications may at times be held in higher esteem than quality or relevance. A recognised thorny issue, but greater care and attention should be placed on validating publication rather than restricting the focus to a mere counting of numbers.
I should also like to highlight another important aspect. To open up research to new areas and gain more progress in waste management, an interdisciplinary research field is required. This approach is indeed already required for larger joint research projects, but implementation is not an easy task. First of all, appropriate partners from other disciplines need to be identified; although we may all have colleagues who study other disciplines and would be willing to cooperate, in my view interdisciplinary research is complicated by the fact that each discipline uses its own "language". Communicate therefore becomes an issue. As an example, a cooperation between social scientists and environmental engineers is rendered problematic due to the difficulty for an engineer to understand the "language" social scientists use, and probably vice versa. The reason as to why each discipline uses a specific "language" and how important this may be falls beyond the scope of this article, but I confess that this situation is a barrier not only for mutual learning but also for distributing results to the public. At times I feel that scientific work that is easy to grasp is not "real science", - science needs to be cleverly packaged to be accepted in an academic circle, sometimes it seems to me a bit as "l'art pour l'art".

I strongly believe that we should present ideas, processes and scientific results in publications in a "simpler", interdisciplinary, more understandable, but of course, correct way. This is not easy. On the other hand, when it comes to the acceptance of highly specific and detailed research by colleagues working in the same field, to enhance communication use of the field-specific "language" may be necessary. We must however strive to find ways to communicate our specific messages in an easy understandable way to other disciplines and the public. This aspect has become even more important following the increasing use of electronic media in the dissemination of results from research, reflections and investigations - we should not entrust this task to non-experts.

Over a period of 12 years I chaired a joint project in which natural scientists and engineers - both from different disciplines -worked together on the treatment of contaminated soils. In the first year we had to learn to communicate and mutually understand each other, at times being required to grasp different approaches used in dealing with specific issues. At the outset, the presentation of intermediate research reports was complex, but by continuously asking questions, we were able to overcome this difficulty to work successfully together and we all learnt a lot from each other; I think that my biggest gain in knowledge was 

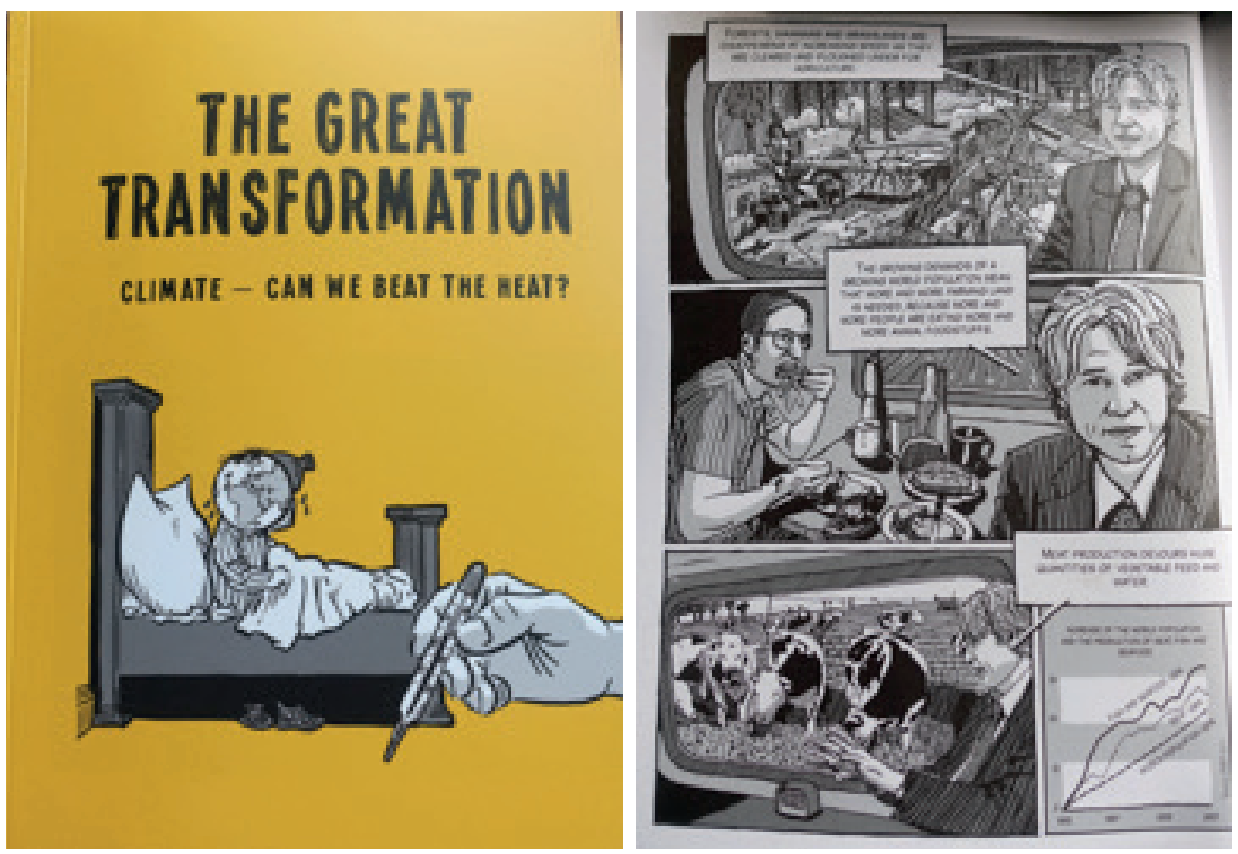

FIGURE 1: The Great Transformatiom, Climate - can we ban the heat? (Anonymous, 2014).

obtained through cooperating in this project.

An interesting example of the presentation of scientifically correct facts and processes is given in a cartoon well- prepared by the German Advisory Council Germany (WBGU) (Anonymous, 2014). This is addressed to the general public and is available free of charge. We need more of these approaches.

I should also like to draw your attention to another point. This relates to the frequently stringent rules that papers submitted for publication have to meet. The presentation of strategy papers, visions or overviews may not be allowed as they do not meet the set requirements. However, at times, the above papers may actually have a higher scientific and public impact than research on a highly specific topic. I suggest that these regulations should be reviewed. Of course, these strategy or position papers would need to be sent out for peer review whilst bearing in mind potentially amended acceptance criteria.

During my career as a reviewer, I have also noticed issues relating to citation. This is not a huge issue, but in my view, particularly with regard to publications received from young researchers, an abundance of citations may be present. Although an exaggeration, levels of citations are at times along the lines of "there is less rainfall in the desert than in tropical areas". This is common knowledge and needs no citations. The authors' own thoughts and ideas would be more relevant may not necessarily need extensive use of citations. We should be more creative and self - confident of our own ideas rather than relying heavily on the work of others. I agree that it is essential to refer to the results and experiences of other colleagues in a research project, this is not the point, but when presenting your own ideas citation may not be needed. Of course, to a certain extent this is the result of the widely adopted publication policies: extensive citations are seen to add to the value of the paper; this may at times be true, but there is ample room for manipulation.

To continue - if authors are cited are we sure that the messages and/or results conveyed are correct? Do we know all the circumstances and conditions as to how the cited results have been elaborated? Do we always demonstrate the correctness of mathematical modelling presented? Citations are ultimately the responsibility of the authors, who have used citations that were a best fit with their own research. Particularly in view of the enormous number of new journals, frequently open access, it has become more difficult to judge the correctness of published papers.

Just to clarify, literature review for scientific work is of course fundamental, and correct citation is naturally part of this scientific work; it is however imperative that the content should be critically reviewed prior to citing it - never make the mistake of merely citing a paper on the grounds of it being published in a peer reviewed journal (which of course should provide more confidence). My advice is to undertake a more extensive search of publications relating to the specific subject of interest. Critical judgement should always be applied.

It may take a long time before we succeed in modifying the world of scientific publication, but perhaps from time to time we should rethink and discuss procedures that have developed over the years and that produce such a significant influence on scientific work.

\section{Rainer Stegmann}

TuTech Innovation $\mathrm{GmbH}$, Germany

stegmann@tuhh.de

\section{REFERENCE}

Anonymous, 2014, The Great Transformatiom, Climate - can we ban the heat?, WBGU, German Advisory Council on Global Change, Verlagshaus Jacoby\&Stuart, Berlin, www.die-grosse-transformation.de 